\title{
A coplanar waveguide tapered slot antenna with beam switching capabilities
}

\author{
D. Abijuru' ${ }^{1}$, M. R. Hamid ${ }^{2}$, N. Seman ${ }^{3}$, M. Himdi ${ }^{4}$ \\ ${ }^{1,2,3}$ Department of Communication Engineering, Universiti Teknologi Malaysia (UTM), Malaysia \\ ${ }^{4}$ Institute of Electronics and Telecommunications of Rennes (IETR), Universite de Rennes 1, France
}

\begin{tabular}{l}
\hline Article Info \\
\hline Article history: \\
Received Feb 10, 2020 \\
Revised Apr 11, 2020 \\
Accepted Apr 25, 2020 \\
\hline
\end{tabular}

Keywords:

Beam switching

Pattern reconfigurability

Radiating elements

Tapered slot antenna

Wireless communication

\begin{abstract}
A wideband tapered slot antenna (TSA) with three radiating elements for beam switching purpose is presented in this paper. The integrated radiating taper slots in assistance with metal strips acting as switches provided the proposed design with the capability of switching its beam into three different directions while maintaining the antenna performance stable. To verify the accuracy of the presented design, the prototype was fabricated and measurements were conducted in terms of scattering parameter (S11), radiation pattern and realized gain towards the three different operating modes. By sequentially, activating the switches, the antenna main beam rotated $90^{\circ}$ in the $\mathrm{XY}$ coordinates. A realized gain ranging from 4.3 to 6.4 $\mathrm{dBi}$ and a wide operating bandwidth $((\mathrm{S} 11) \leq-10 \mathrm{~dB})$ from $3.3 \mathrm{GHz}$ to $5 \mathrm{GHz}$ were observed throughout the antenna performance in simulation as well as in experiment. With the covered bands, the proposed antenna is suitable for sub-6GHz communications systems.
\end{abstract}

Copyright $@ 2020$ Institute of Advanced Engineering and Science. All rights reserved.

\section{Corresponding Author:}

Norhudah Seman,

Department of Communication Engineering, Universiti Teknologi Malaysia, Malaysia.

Email: huda@fke.utm.my

\section{INTRODUCTION}

Whilst the advancement of wireless communication systems increases tremendously, diverse steps are required to tackle the exponential growth in broadband demands. Fixed antennas are limited in performance and unable to cope in a dynamic environment. Reconfigurable antennas were introduced to allocate the antenna beam on the target thus, increase the overall data rate and reduce the interference. Reconfigurable antennas are described as antennas that support multiple functions within a single structure. This reconfiguration comes in different form such as frequency reconfiguration, polarization reconfiguration and pattern reconfiguration depending on the required applications [1-7].

In a dynamic environment, avoiding interferences in a wireless system is crucial, such that directive antenna with switched beam ability are required in such situation to improve the communication linkage by ensuring the signal reaches the intended users. This enables effective and consistent communication for fastmoving information transmitting in both base stations and user terminals of wireless systems [8-11]. Towards achieving beam switching, various approaches have been studied, namely digital beam forming [12-15]. However, this approach is limited to narrow operating band and quite complex. The current approaches are parasitic tuning and multiple radiators, which are widely employed due to the ease of integration [16-22]. In this work, switched radiators approach is proposed to provide a wide tilt angle of $\pm 90^{\circ}$ over a wide operating band and a portion of common area is overlapped for miniaturized profile. The beams are configured by channelling the current flows to the radiating slot. The proposed structure conquered the limitation of $\pm 40^{\circ}$ in the tilt angle as reported in [23-25]. The existing studies shows that with a wide operating bandwidth, the beam switching directions are limited to two states at the highest gain of $6 \mathrm{dBi}$ [26, 27]. 
Contrary to the previous works, the proposed structure presents a trade-off between bandwidth coverage and beam switching states with three directive beams at the peak gain of $6.4 \mathrm{dBi}$. An exception is exhibited in [28] with 16 states, every $22.5^{\circ}$ covering a narrow bandwidth at the peak gain of $6.2 \mathrm{dBi}$. Nevertheless, the design proposed in this work is a good candidate for wide-beam steering applications. The merits of the proposed structure over previous reported works is the fact that different modes can be combined to boost the reconfigurable states (from 3 states to 7 states without additional switches) and improve the directivity. However, this will be examined in the next study.

\section{DESIGN AND EXPERIMENT}

The proposed TSA is built from an original TSA with one radiating element. The design is optimized with additional taper slots to increase the reconfigurable states. The proposed design and its parameters is displayed in Figure 1 and Table 1. The top layer engraves three taper slots radiators whereas the lower patch of the antenna grooves of a cpw feed and delay slot-line for wideband matching purpose. An FR4 with $0.8 \mathrm{~mm}$ of substrate thickness board is used with a relative permittivity of 4.3 and a tangent loss of 0.025 . The characteristic impedance was selected to be $50 \Omega$. Initially, the energy is conveyed from CPW to radiating- slot by a delay slot-line with a basic role of upholding the electric field in phase with the other slot-line. Towards the end of the delay slot-line, the two electric fields stayed in phase for wide transmission capacity to be acquired. Secondly, the wave propagations are directed by the taper slot respecting the orientation of the switched radiator. The fabricated prototypes are depicted in Figure 2.

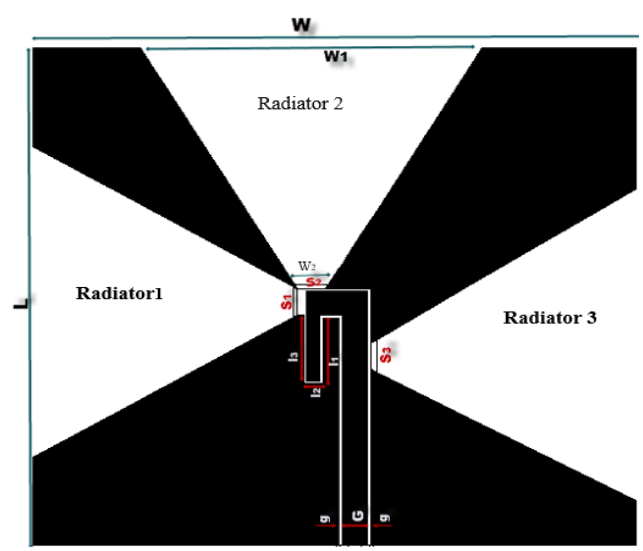

Table 1. Optimized parameters of the

\begin{tabular}{cr}
\multicolumn{2}{c}{ designed antenna } \\
\hline Variable & Dimension $(\mathrm{mm})$ \\
\hline $\mathrm{W}$ & 112.84 \\
$\mathrm{~W}_{1}$ & 63.8 \\
$\mathrm{~W}_{2}$ & 5.39 \\
$\mathrm{~L}$ & 102 \\
$\mathrm{l}_{1}$ & 13.39 \\
$\mathrm{l}_{2}$ & 2.48 \\
$\mathrm{l}_{3}$ & 13.95 \\
$\mathrm{G}$ & 4.84 \\
$\mathrm{~g}$ & 0.56 \\
$\mathrm{~S}_{1,2,3}$ & 5.39 \\
\hline
\end{tabular}

Figure 1. Proposed antenna design structure

In order to achieve the three different modes, the metals strips acted as switches, ideally, for radiator 1 to operate, $S_{1}$ is open whereas $S_{2}$ and $S_{3}$ are short-circuited meaning that metal strips are added on to prevent the current to flow in to the radiator 2 and 3 . On the other hand, $S_{1}$ and $S_{3}$ are short-circuited blocking the current in the left and right modes and allowing the up mode to radiate. Whereas for right mode to be functional, $\mathrm{S}_{1}$ and $\mathrm{S}_{2}$ should be short-circuited.
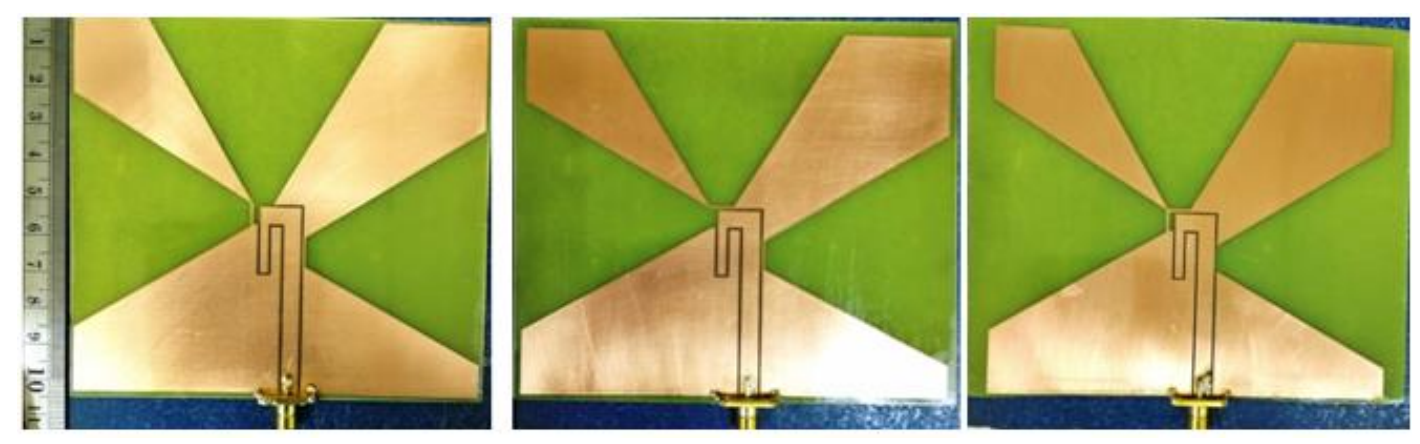

Figure 2. Fabricated prototype with metal strips in up, left and right mode 


\section{RESULTS AND ANALYSIS}

In this study, performance evaluation as technical result style is implemented. The designed antenna as shown in Figure 1 was simulated using computer simulation technology (CST), fabricated and measured to rationalize the accuracy of the proposed beam tilt technique. The performance of the antenna in terms of reflection coefficient was measured using E5071C network analyzer while the radiation patterns were carried out in a SATIMO anechoic chamber.

The feed transition is a major criteria for wideband operation. In this work, the introduction of delay line between radiating slot and CPW was used to provide a broader matching. Overall, a good matching under the condition $\left(\mathrm{S}_{11} \leq|-10| \mathrm{dB}\right)$ from $3.3 \mathrm{GHz}$ to $5 \mathrm{GHz}$ is observed, this implies that $90 \%$ of signal was transmitted with $10 \%$ being reflected. Figure 3 highlights the return loss curves base on the switched radiating slot. A shift of $100 \mathrm{MHz}$ is observed as the radiating slot moves farther from the delay line. This discrepancy is probably due to the delay matching slot-line, however, the wideband is preserved.
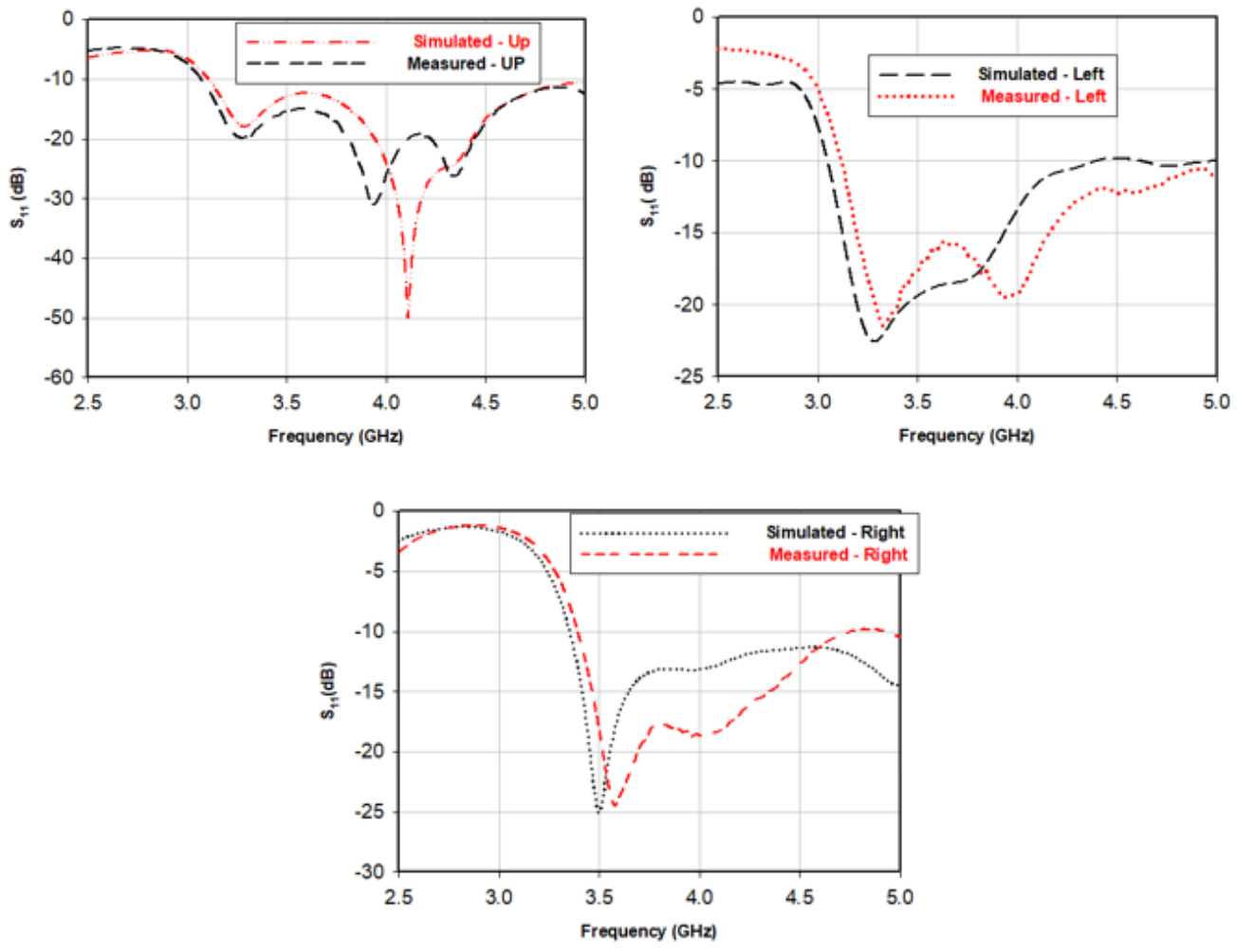

Figure 3. Simulated vs measured $S_{11}$ in up, left and right mode

Based on the theory guiding TSA, the beam direction depends on the orientation of the radiators, the beam angle can simply be adjusted if the orientation of the radiator is changed. In this work, the beam can be configured by channelling the current flows to the radiating slot. This technique is flexible, reduces interference from unwanted source and allow increased performance over dipole antennas or omnidirectional antennas. The capacity of the antenna to switch the main beam towards the intended directions while covering a wide tilt angle $\pm 90^{\circ}$ is assessed in the XY coordinates and fitted the main objective of this study. A good agreement is observed between measurement and simulation for the three different directions at three different operating frequencies.

It can be seen from Figure 4, at the three examined frequencies, the primary lobe is obtained at phi equals to $0^{\circ}$ with less side lobes in the up mode with fixed theta at $90^{\circ}$ for the E-phi component in the XY coordinates. By short-circuiting $S_{2}$ and $S_{3}$, the current flows towards the left mode, as results, the main lobe switched from phi equals to $0^{\circ}$ to phi equals to $-90^{\circ}$ as depicted in Figure 5. The same method is applied to direct the current to the right mode as shown in Figure 6 by opening $S_{3}$. Consequently, the pattern beams are controlled. It is observed that the gain does not change dramatically for the three modes with a peak gain of $6.4 \mathrm{dBi}$ and a minimum gain of $4.3 \mathrm{dBi}$. The proposed structure rises above the limitation of $\pm 40^{\circ}$ in the tilt angle as reported in [23-25]. This research work is based on a tapered slot antenna known as a directive antenna with end-fire characteristics and symmetric pattern in both co-and cross-polarization. 


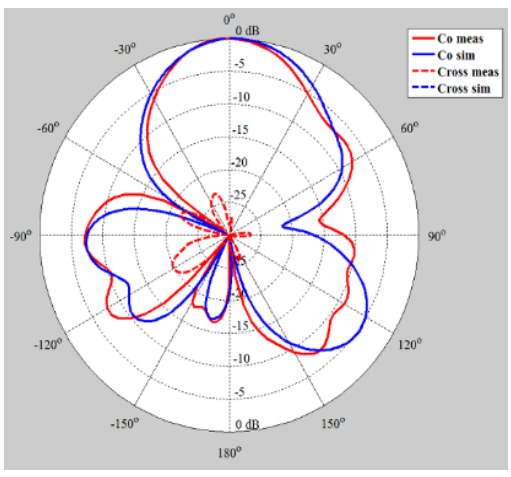

(a)

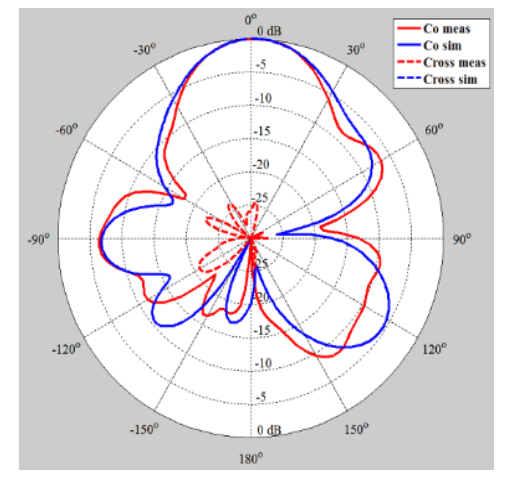

(b)

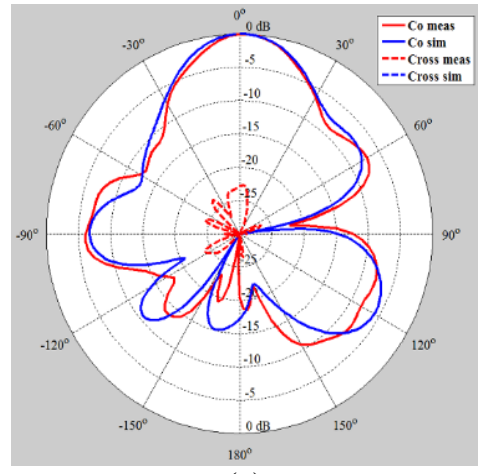

(c)

Figure 4. E-phi component co and cross (sim vs meas)-up mode (a) $3.4 \mathrm{GHz}$, (b) $3.6 \mathrm{GHz}$, (c) $3.8 \mathrm{GHz}$

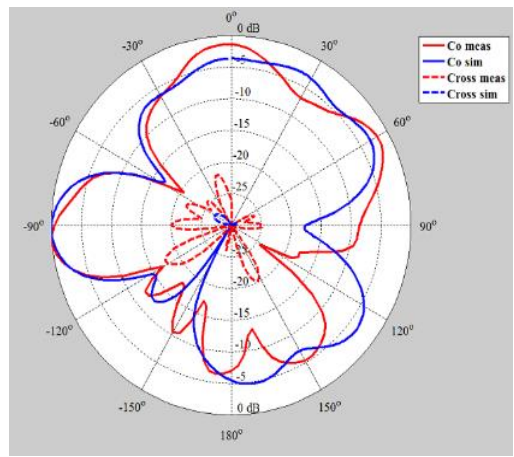

(a)

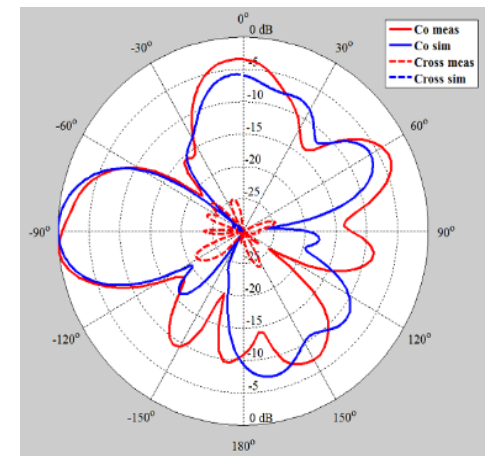

(b)

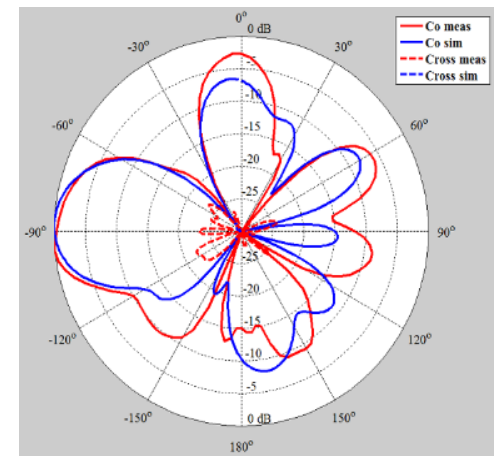

(c)

Figure 5. E-phi component co and cross (sim vs meas)- left mode (a) $3.4 \mathrm{GHz}$, (b)3.6GHz, (c) $3.8 \mathrm{GHz}$

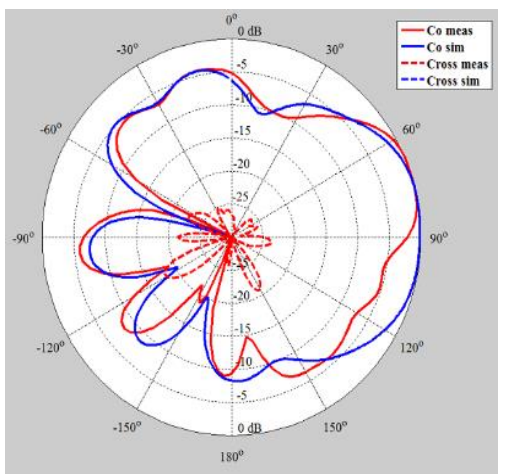

(a)

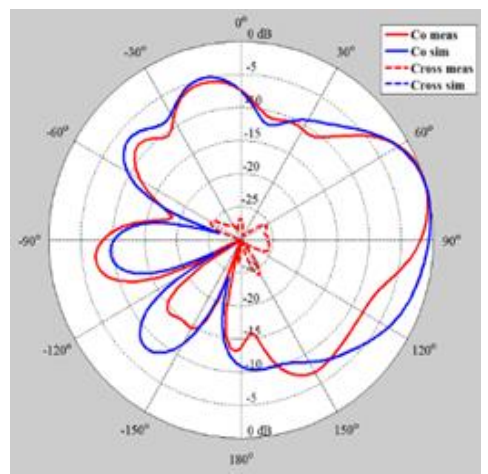

(b)

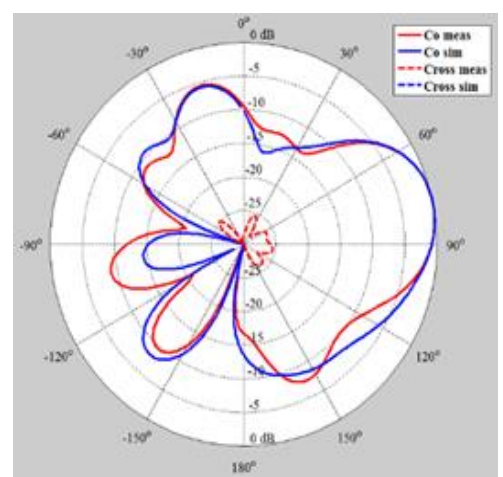

(c)

Figure 6. E-phi component co and cross (sim vs meas)-right mode (a) $3.4 \mathrm{GHz}$, (b) $3.6 \mathrm{GHz}$, (c) $3.8 \mathrm{GHz}$

\section{CONCLUSION}

A wideband tapered slot antenna with beam switching capabilities is presented in this monograph. The viability of switching the main beam with respect to the intended directions not affecting its operating bandwidth was evaluated. The proposed design achieved three different directions with a realized gain ranging from 4.3 to $6.4 \mathrm{dBi}$. The total efficiency varies from $92 \%$ in simulation to $60 \%$ in experiments. Furthermore, it is suggested to explore the performance of the design in active mode without the increment in size and the disturbance in the pattern. 


\section{ACKNOWLEDGEMENTS}

The authors would like to thank Organization for Women in Science for the Developing World (OWSD), Swedish international development cooperation agency (Sida). The authors also would like to acknowledge Wireless Communication Center (WCC), Universiti Teknologi of Malaysia and University of Rennes 1 for supporting this work.

\section{REFERENCES}

[1] R. L. Haupt and M. Lanagan,"Reconfigurable antennas," IEEE Antennas and Propagation Magazine, vol. 55, no. 1, pp. 49-61, 2013.

[2] R. Sabapathy, M. F. B.Jamlos, R. B. Ahmad, M. Jusoh, M. I. Jais, M. R. Kamarudin, "Electronically reconfigurable beam steering antenna using embedded rf pin based parasitic arrays (erppa)," Progress in Electromagnetics Research (PIER), vol. 140, pp. 241-261, 2013.

[3] X. Ding and B. Z. Wang, "A novel wideband antenna with reconfigurable broadside and endfire patterns," IEEE Antenna and Wireless Propagation Letters, vol. 12, pp. 995-998, 2013.

[4] X. S. Yang, W. Q. Deng, C. S. Shen and B. Z. Wang, "Dual-polarized multi-layer patch antenna with pattern reconfigurable characteristic," in 2016 IEEE 5th Asia-Pacific Conference on Antennas and Propagantion (APCAP), Kaohsiung, pp. 181-182, 2016

[5] A. Dadgarpour, M. S. Sorkherizi, T. A. Denidni and A. A. Kishk, "Passive beam switching and dual-beam radiation slot antenna loaded with enz medium and excited through ridge gap waveguide at millimeter-waves," IEEE Transactions on Antenna and Propagation, vol. 65, no. 1, pp. 92-102, 2017.

[6] R. Wu, Q. X. Chu, "Resonator-loaded broadband antenna for lte700/gsm850/gsm900 base stations," IEEE Antenna and Wireless Propagation Letters, vol. 16, pp. 501-502, 2017.

[7] M. Safaron, H. A. Majid, B. A. F. Esmail, A. S. Ab. Ghafar, F. A. Saparudin, M. F. Ismail and M. A. Abdullah, "Design and compact reconfigurable uwb antenna with wimax and wlan band rejection," Indonesian Journal of Electrical Engineering and Computer science (IJEECS), vol. 17, no. 3, pp. 1427-1433, 2020.

[8] N. F. Miswadi and M. T. Ali, "Directional cloverleaf antenna for unmanned aerial vehicle (UAV) application," Indonesian Journal of Electrical Engineering and Computer science (IJEECS), vol. 14, no. 2, pp. 773-779, 2019.

[9] M. S. Alam and A. Abbosh, "Beam-steerable planar antenna using circular disc and four pin-controlled tapered stubs for wimax and wlan applications, " IEEE Antennas and Wireless Propagation Letters, vol. 15, pp. 980-983, 2016.

[10] F. F. Manzillo, M. S.'mierzchalski, L. Le Coq, M. Ettorre, J. Aurinsalo, and K. T. Kautio, "A wide-angle scanning switched-beam antenna system in LTCC technology with high beam crossing levels for v-band communications," IEEE Transactions on Antennas and Propagation, vol. 67, no. 1, pp. 541-553, 2019.

[11] G. M. Zhang, J. S. Hong, G. Song and B. Z. Wang, "Design and analysis of a compact wideband patternreconfigurable antenna with alternate reflector and radiator," IET Microwaves, Antenna and Propagation, vol. 6, no. 15, pp. 1629-1635, 2012.

[12] Y. Li, Z. Zhang, J. Zheng, Z. Feng and M. F. Iskander, "Experimental analysis of a wideband pattern diversity antenna with compact reconfigurable cpw-to-slotline transition feed," IEEE Transactions on Antenna and Propagation, vol. 59, no. 11, pp. 4222-4228, 2011.

[13] B. Z. Wang, S. Xiao, Y. Y. Bai and G. M. Zhang, "Researches on pattern reconfigurable antennas and its application in phased array," 2011 Intenational Workshop on Antenna Technology (iWAT), Hong Kong, pp. 46-49, 2011.

[14] K. Liu, Y. Cheng, Y. L. Qin, X. Li and Y. Jiang, "Radiation pattern control and synthesis for the generation of oambeams," 2016 Progress in Electromagnetics Research Symposium (PIERS), Shanghai, pp. 2202-2205, 2016.

[15] Y. Cai and Z. Du, "A novel pattern reconfigurable antenna array for diversity systems," IEEE Antenna and Wireless Propagation Letters, vol. 8, pp. 1227-1230, 2009.

[16] Y. Juan, W. Che, W. Yang and Z. N. Chen, "compact pattern-reconfigurable monopole antenna using parasitic strips," IEEE Antenna and Wireless Propagation Letters, vol. 16, pp. 557-560, 2017.

[17] J. Ren, X. Yang, J. Yin and Y. Yin, "A novel antenna with reconfigurable patterns using h-shaped structures," IEEE Antenna and Wireless Propagation Letters, vol. 14, pp. 915-918, 2015.

[18] M. Alam and A. Abbosh, "Wideband pattern-reconfigurable antenna using pair of radial radiators on truncated ground with switchable director and reflector," IEEE Antenna and Wireless Propagation Letters, vol. 16, pp. 24-28, 2017.

[19] Z. L. Lu, X. X. Yang and G. N. Tan, "A wideband printed tapered-slot antenna with pattern reconfigurabilty," IEEE Antenna and Wireless Propagation Letters, vol. 13, pp. 1613-1616, 2014.

[20] D. Abijuru, M. R. Hamid, and A. N. Obadiah, "Improved Vivaldi antenna with radiation pattern control features," TELKOMNIKA (Telecommunication, Computing, Electrics and Control), vol. 16, no. 3, pp. 1143-1149, 2018

[21] Y. yang and X. Zhu, "A wideband reconfigurable antenna with 360 beam steering for 802.11ac wlan applications," IEEE Transactions on Antennas and Propagation, vol. 66, no. 2, pp. 600-608, 2018.

[22] D. Abijuru, M. Hamid, N. Seman and M. Himdi, "Broadband cloverleaf Vivaldi antenna with beam tilt characteristics," International Journal of RF and Microwave Compuer-Aided Engineering, vol. 30, no. 5, 2018.

[23] W. Lin, H. Wong and R. W. Ziolkowski, "Wideband pattern-reconfigurable antenna with switchable broadside and conical beams," IEEE Antenna and Wireless Propagation Letters, vol. 16, pp. 2638-2641, 2017.

[24] J. Wang, J. Yin, H. Wang, C. Yu and W. Hong, "Wideband U-slot patch antenna with reconfigurable radiation pattern," 2017 11th European Conference on Antennas and Propagation (EUCAP), Paris, pp. 611-615.2017. 
[25] D. Subramaniam, M. J. Jusoh, T. Sabapathy, M. N. Osman, M. R. Kamarudin, R. R. Othman and M. R. Awal, "A compact high-gain parasitic patch antenna with electronic beam switching," Indonesian Journal of Electrical Engineering and Computer science (IJEECS), vol. 13, no. 2, pp. 551-555, 2019.

[26] Y. Dong, J. Choi and T. Itoh, "Vivaldi antenna with pattern diversity for 0.7 to $2.7 \mathrm{GHz}$ cellular band applications," IEEE Antenna and Wireless Propagation Letters, vol. 17, no. 2, pp. 247-250, 2018.

[27] S. Tebache, F. Ghanem and A. Belouchrani, "Novel and simple approach for reconfiguring the pattern of an uwb cpw-fed monopole antenna," 2017 Seminar on Detection Systems Architectures and Technologies (DAT), Algiers, pp. 1-5, 2017.

[28] L. Ge, K. M. Luk and S. Chen, " $360^{\circ}$ beam- steering reconfigurable wideband substrate integrated waveguide horn antenna," IEEE transactions on Antennas and Propagation, vol. 64, no. 12, pp. 5005-5011, 2016.

\section{BIOGRAPHIES OF AUTHORS}

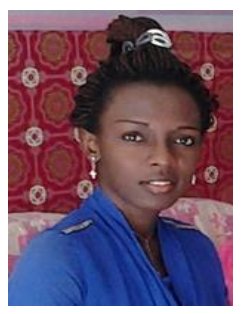

Abijuru Delphine received her Bachelor of Engineering (B.Eng.) in Electrical and Telecommunications Engineering from the National University of Rwanda, Huye, Rwanda in 2012 and a Master of Engineering (M.Eng.) in Communication Engineering from the Universiti Teknologi Malaysia in 2014. She has been pursuing her $\mathrm{PhD}$ degree in Communication Engineering at the Universiti Teknologi Malaysia (UTM) since 2017. Her research interest includes Radio frequency devices, beam switching antenna, phase shifters.

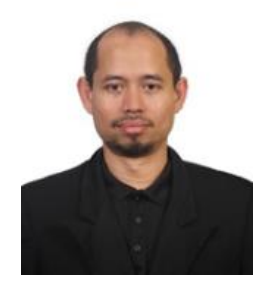

Mohamad Rijal Hamid received the M.Sc. degrees in communication engineering from the Universiti Teknologi Malaysia, Johor Bahru, Malaysia, in 2001 and the Ph.D Degree at the University of Birmingham, Birmingham, U.K. in 2011. He has been with Universiti Teknologi Malaysia (UTM) at the Faculty of Electrical Engineering (FKE), UTM, since 1999. Currently his position is a Senior Lecturer. His major research interest is reconfigurable antenna design for multimode wireless applications.

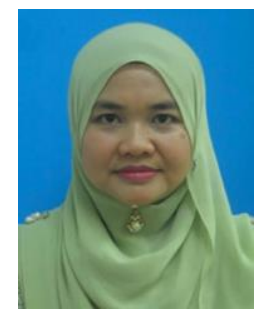

Norhudah Seman received the B. Eng. in Electrical Engineering (Telecommunications) degree from Universiti Teknologi Malaysia, Johor, Malaysia, in 2003 and M.Eng. degree in RF/Microwave Communications from The University of Queensland, Brisbane, St. Lucia, Qld., Australia, in 2005. In September 2009, she completed her Ph.D. degree at The University of Queensland. Currently, she is an Associate Professor and Director (Communication Engineering) in School of Electrical Engineering and Research Fellow in HiCoE Wireless Communication Centre (WCC), Universiti Teknologi Malaysia. Her research interests concern the design of microwave/millimeter wave devices for biomedical and industrial applications, effects of electromagnetic

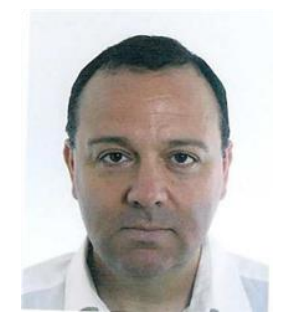

Mohamed Himdi received the Ph.D. degree in signal processing and telecommunications from the University of Rennes 1, France in 1990. Since 2003, he has been a Professor with the University of Rennes 1, and the Head of the High Frequency and Antenna Department until 2013, of IETR. He has authored or co-authored 130 journal papers and over 270 papers in conference proceedings. He has also co-authored 9 book chapters. He holds 40 patents. His research activities concern passive and active millimeter-wave antennas. His research also includes development of new architectures of antenna arrays, and new three-dimensional (3-D) antenna technologies. He was Laureate of the 2d National Competition for the Creation of Enterprises in Innovative Technologies in 2000 (Ministry of Industry and Education). In March 2015 he received the JEC-AWARD at Paris on Pure composite material antenna embedded into a motorhome roof for the Digital Terrestrial Television reception. 